\title{
Mechanism of formation of volcanic bombs: insights from a pilot study of anisotropy of magnetic susceptibility and preliminary assessment of analytical models
}

\author{
Edgardo Cañón-Tapia ${ }^{1}$ (iD
}

Received: 1 February 2017 / Accepted: 23 May 2017 /Published online: 6 June 2017

(C) The Author(s) 2017. This article is an open access publication

\begin{abstract}
Volcanic bombs and achneliths are a special type of pyroclastic fragments formed by mildly explosive volcanic eruptions. Models explaining the general shapes of those particles can be divided in two broad categories. The most popular envisages the acquisition of shapes of volcanic bombs as the result of the rush of air acting on a fluid clot during flight, and it includes many variants. The less commonly quoted model envisages their shapes as the result of forces acting at the moment of ejection of liquid from the magma pool in the conduit, experiencing an almost negligible modification through its travel through air. Quantitative evidence supporting either of those two models is limited. In this work, I explore the extent to which the anisotropy of magnetic susceptibility (AMS) might be useful in the study of mechanisms of formation of volcanic bombs by comparing measurements made on two spindle and two bread-crusted bombs. The results of this pilot study reveal that the degree of anisotropy of spindle bombs is larger, and their principal susceptibility axes are better clustered than on bread-crusted bombs. Also, the orientation of the principal susceptibility axes is consistent with two specific models (one of the in-flight variants and the general ejection model). Consequently, the reported AMS measurements, albeit limited in number, indicate that it is reasonable to focus attention on only two specific models to explain the acquisition of the shapes of volcanic bombs. Based on a parallel theoretical assessment of analytical models, a third alternative is outlined,
\end{abstract}

Editorial responsibility: V. Acocella

Edgardo Cañón-Tapia

ecanon@cicese.mx

1 Centro de Investigación Científica y de Educación Superior de Ensenada (CICESE)- Carretera Tijuana-Ensenada, \# 3918, Col. Pedregal Playitas, CP. 22860 Ensenada, Baja California, Mexico envisaging volcanic bomb formation as a two-stage process that involves the bursting of large $(\sim \mathrm{m})$ gas bubbles on the surface of a magma pond. The new model advanced here is also consistent with the reported AMS results, and constitutes a working hypothesis that should be tested by future studies richer in data. Fortunately, since this work also establishes that AMS can be used to determine magnetic fabric in small size samples, the possibility to expand this study to a larger collection of bombs is granted.

Keywords Volcanic bombs · Anisotropy $\cdot$ Magnetic susceptibility

\section{Introduction}

Volcanic bombs are officially defined by the International Union of Geological Sciences (IUGS) as pyroclasts thrown into the air during a volcanic eruption, with mean diameter commonly >64 mm (Schmid 1981). Unlike blocks, which are typically angular, bombs tend to have smooth surfaces, and many retain structures that suggest fluid deformation. From a genetic point of view, the lower size limit does not have a clear physical meaning, and it was considered as provisional (Schmid 1981). As more recent observations indicate, fluid deformation features can be identified on fragments with diameters less than $1 \mathrm{~cm}$ (Cas and Wright 1987; Macdonald et al. 1986; Lockwood and Hazlett 2010), and although not acknowledged by the IUGS commission, such particles were formally called achneliths by Walker and Croasdale (1972). Thus, identification of a continuum between bombs and achneliths (all hereafter in this paper referred to simply as bombs) suggests that their shape acquisition mechanism is not size limited. Nevertheless, the association between 
specific parameters and the acquisition of specific bomb shapes remains ill-explored.

From a microscopic perspective, the relation between particle morphology and eruptive and transport mechanisms has been abundantly explored (e.g., Dellino and Liotino 2002; Ersoy et al. 2006, 2008; Heiken and Wohletz 1985; Leibrandt and Le Pennec 2015; Liu et al. 2015; Rausch et al. 2015; Riley et al. 2003; Sheridan and Kortemeier 1987; Sheridan and Marshall 1983; Vonlanthen et al. 2015). Heiken (1972) considered that the shape of particles in the ash size range is mostly dependent on the shape of magmatic gas bubbles at the moment of fragmentation: flat and platy shards arise from broken vesicle walls, and droplet shapes are produced from low viscosity magma where the effect of surface tension is likely to become more important. Also, Shimozuru (1994) provided the only available theoretical model addressing the formation of glass threads in a volcanic context. The extent to which those mechanisms remain valid for particles $>1 \mathrm{~mm}$ in diameter, however, is unclear.

From a macroscopic point of view, the general opinion of most workers since the early 1900 's, and the most popular explanation is that the main forces responsible for the acquisition of the final shape of volcanic bombs act during transport from the vent to the landing site (Carracedo Sánchez et al. 2009; Fisher and Schminke 1984; Francis 1995; JunqueiraBrod et al. 1999; Lockwood and Hazlett 2010; Reck 1915; Wentworth and Macdonald 1953). As it will be shown below, there are many variants of this general model, all of which can be loosely referred to as the in-flight model of bomb formation. A less common explanation, that can be referred to as the ejection model, concerns processes taking place at the moment of ejection from a magma pool, and that there is negligible change to the shapes of bombs during their travel through air (Ollier 1988; Reck 1915; Tsuya 1941; Walker and Croasdale 1972; Williams and McBirney 1979). With some variants, this mechanism is similar to that used to explain the formation of Pele's hair and Pele's tears (Walker and Croasdale 1972; Shimozuru 1994). In addition to those two general models, the association of key morphological features of bombs with specific eruption or transport conditions has been established, for very specific morphological types (Benage et al. 2014; Carracedo Sánchez et al. 2010; Carracedo Sánchez et al. 2009, 2015; Simakin et al. 1999; Wright et al. 2007). Nevertheless, from a general point of view, the mechanism of formation of volcanic bombs and the factors influencing the acquisition of their general shape remain relatively unexplored.

In an effort to obtain quantitative evidence that could be used to identify the main factors controlling the general shape of volcanic bombs, and to discriminate between alternative models of formation, a pilot study of the anisotropy of magnetic susceptibility (AMS) of four volcanic bombs was completed. Since AMS measurements have never been reported from volcanic bombs, it was unclear whether this method could be adopted to detect systematic variations of deformation within a single bomb, or even if it could detect a significant difference between bombs of two different morphological types. Consequently, the primary objective of this study is to determine to what extent AMS might be useful in that context. As shown below, AMS not only has the potential to provide quantitative evidence so far absent in the study of volcanic bombs, but also can be used to favor two specific mechanisms of formation. Furthermore, the information provided by the currently limited AMS results, in combination with a preliminary theoretical assessment of those two specific models, allows us to outline a working hypothesis that should be tested with more data. In any case, even if only qualitatively at this stage, the obtained results suggests that in-flight forces are not the only mechanism of acquisition of the shape of volcanic bombs.

\section{Bomb morphology and genesis}

As many as 14 different shapes have been identified among the bombs of one single volcano (Tsuya 1939, 1941). Distinction between some of those shapes might be subtle, however, and it is not clear whether identification of that many categories provides some insight concerning their genesis. A less detailed classification scheme was proposed by Reck (1915), who focused on broad features rather than on specific shapes, dividing bombs in three groups. Besides a classification based on the external characteristics of volcanic bombs (Fig. 1a), it is possible to identify various bomb types by examining their internal structure. Reck (1915) and Tsuya (1941) distinguished three main types of internal structures. The first two types have a central core: a solid fragment on the first group and an empty cavity (interpreted to be the remnant of a large bubble) in the second group. Bombs in the third group lack any type of central core. Within these three main groups, some subdivisions can be documented, such as a concentric shell structure of alternating vesicles and massive lava, or a continuous massive or vesicular structure. Two key points mentioned by Reck (1915), however, are that almost all varieties of internal structure can be found in any of the groups of outer shapes, and that therefore there is only a weak correspondence between the internal structure and the outer shape of bombs. Consequently, as illustrated on Fig. 1b, a scheme of classification having nine different classes can be devised by combining the three main external shapes with the three main types of internal structures. The advantage of this scheme is that it allows us to incorporate gas expansion as an agent in controlling final bomb shape with relative facility.

Walker (1969) identified three basic types of bombs, all of which depend on the amount of gas expansion experienced during cooling (which starts at the moment of ejection from the crater). Walker's first group includes dense clots, probably hot upon impact, but that nonetheless do not experience any gas expansion. The second group is defined by bombs 
a) I Spheroidal to ellipsoidal (including irregular ellipsoids)

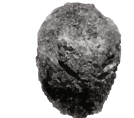

Spheroidal

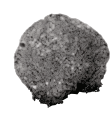

Disk

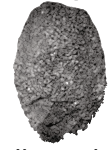

Ellipsoidal

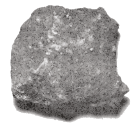

Square

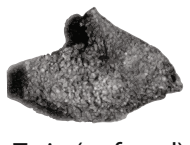

Twin (or fused)

II Ellipsoidal with appendages

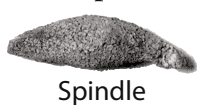

Spindle
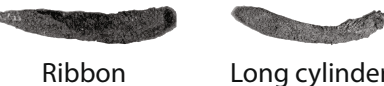

Long cylinder

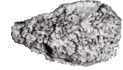

Conical

III Ribbon to band shaped

b)
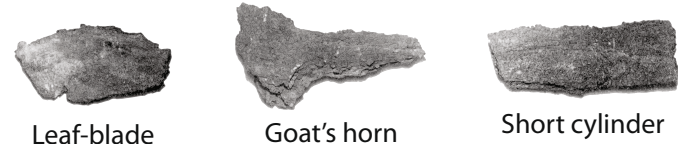

Short cylinder

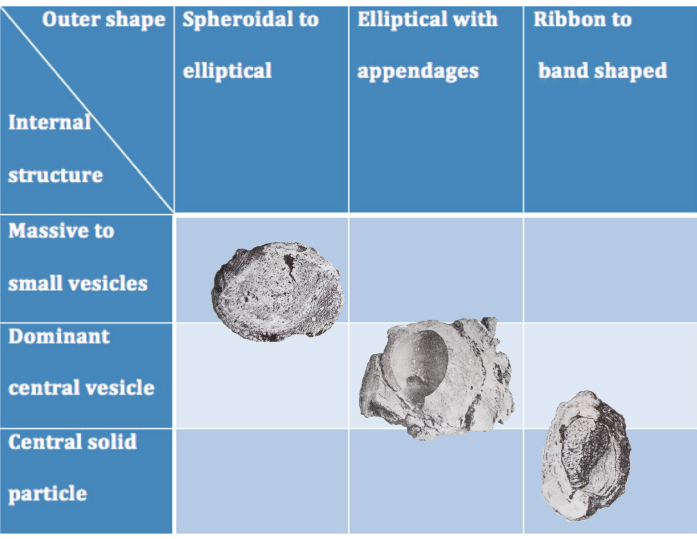

Fig. 1 a 12 morphological types of bombs identified by Tsuya (1939), and their relation with the three general forms identified by Reck (1915). b According to Reck (1915) the outer shape and the internal structure are independent from each other and can combine to produce various types. Three specific examples are shown for illustrative purposes

displaying a quenched rind and limited expansion, and the third group includes highly expanded bombs with glassy crusts and broad shallow cracks. A similar classification was proposed by Wright et al. (2007), although they included an intermediate classification between the two groups showing expansion. As those authors suggested, the difference in the amounts of expansion and on the characteristics of the rinds and cracks of those bombs could be related to the depth of magma in the conduit from which the bomb is ejected, and to the timing of ejection in relation to the cycles of pressurization-loss of pressure that are likely to control vulcanian eruptions. Other studies also point out that some amount of preeruptive volatile loss is required to form the outer rind of the bomb, followed by a post-fragmentation exsolution of gases

(Hoblitt and Harmon 1993). Furthermore, textural differences among bread-crusted bombs have been related to differences in the transport regime (Benage et al. 2014). Despite all of these efforts, however, it remains unclear whether gas expansion is relevant for controlling the overall external shape of bombs or not, or the extent to which this parameter influences the internal structure of the bomb acquired before landing.

Although the preceding paragraphs indicate that the relationship between the internal structure of volcanic bombs and their external shapes remains ill determined, it also points out the necessity to get some type of information about the processes taking place inside a bomb during its formation. Also, it must be considered that not all the variants of the general models of bomb formation are entirely equivalent in terms of the type and amount of shear that they could explain within a given bomb. A detailed analysis of each of the identified variants is beyond the scope of this paper. It suffices for the present purposes to outline the main differences between variants in simplified form. This is done in a latter section, after the information from the AMS measurements has been presented. At this stage, however, it is convenient to identify the variants of the in-flight and ejection models.

Figure 2 summarizes the various mechanisms that have been invoked to explain the most typical shapes of bombs. In the case of in-flight variants, surface tension of lava, drag forces on the surface of the bomb, and centrifugal forces associated to rotation are the predominant factors (Fig. 2a). For the ejection model (Fig. 2b), the main parameters include the shape of the core, the viscosity of the lava and the velocity at which the particle is expelled from the lava pool. As illustrated in Fig. 2c, bread-crusted bombs are characterized by a cracked and checkered surface, which is independent of the overall shape of the bombs. The origin of the characteristic surface is commonly related to gas expansion taking place after the formation of the outer rid, but some amount of thermal contraction might have been important in some cases (Wright et al. 2007). Figure $2 d$ illustrates an alternative mechanism of bomb-formation inspired by the processes described to be important in controlling particle shape at a microscopic level. Details of this model are postponed to later in this paper.

In summary, although the main parameters likely to be involved in the formation of volcanic bombs have been identified for more than a century, we still ignore their relative influence in controlling the general shape of a particular bomb.

\section{Methods}

\section{Anisotropy of magnetic susceptibility}

The anisotropy of magnetic susceptibility (AMS) provides a fast and inexpensive method to determine the average mineral fabric of rock samples. AMS is expressed as a second order 
Fig. 2 Summary of models of formation of bombs. The blue dot at the center of the bombs in Fig. 2a, b depict the probable occurrence of a central core. See text for details a)
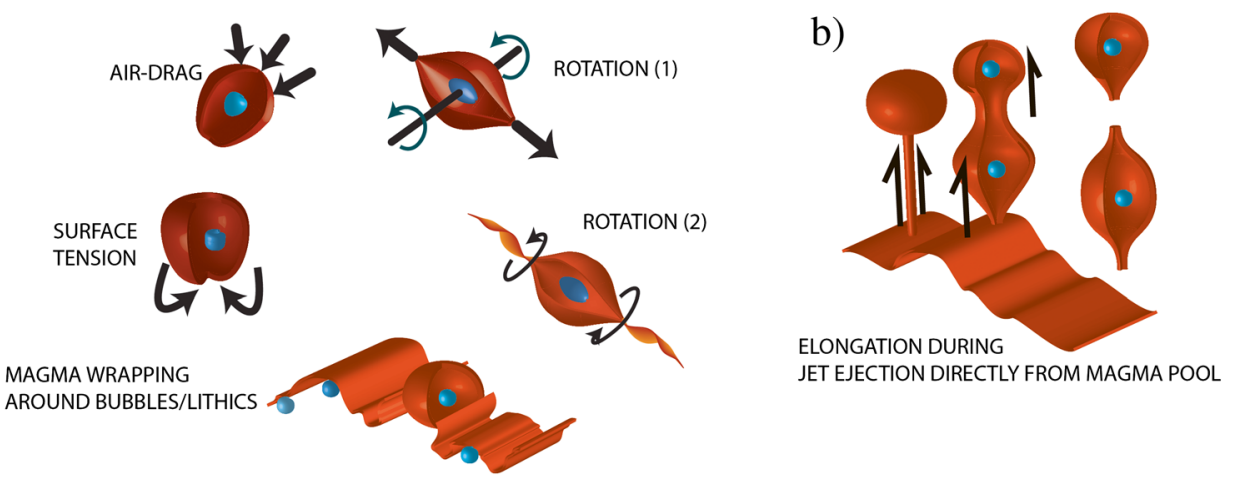

c)

DELAYED GAS EXSOLUTION AND EXPANSION PRODUCE BREADCRUST TEXTURE REGARDLESS

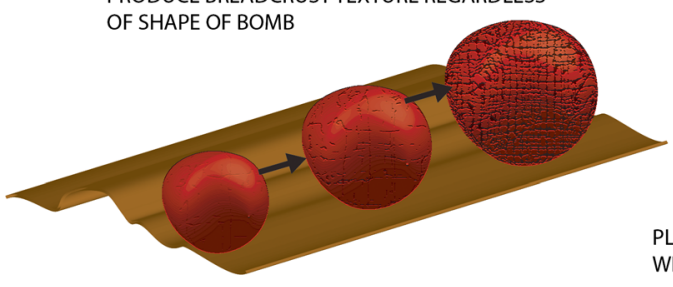

d)

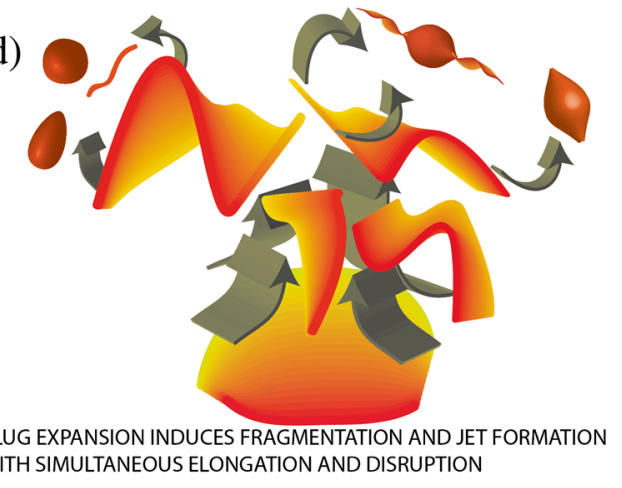

tensor that relates the internal response of a material when exposed to the influence of an external magnetic field. The orientation of the principal susceptibility axes $\left(k_{\max } \geq k_{\text {int }} \geq k_{\min }\right)$ is related to the average orientation of the mineral constituents, whereas bulk susceptibility, degree of anisotropy, and shape of the susceptibility tensor (all scalar quantities) are related to the amount of ferromagnetic minerals present in the rock, the degree of alignment and the geometry of that arrangement.

Attempts to obtain a simple relationship between deformation and some aspect of AMS results (orientation of principal susceptibilites, degree of anisotropy or shape of the associated ellipsoid; e.g., Hrouda 1993; Hrouda et al. 2005; Loock et al. 2008; Petronis et al. 2013) have shown that it is not possible to obtain a universally valid relationship that can be applied to rocks of different composition. This is the case because of the dependence of the AMS on the habit of the minerals present on each sample, and on their degree of alignment, which might be different for each mineral species even in the same sample (Cañón-Tapia and Castro 2004). Consequently, a rigorous quantitative treatment of deformation based only on AMS results seems unjustified. Nevertheless, the available evidence indicates that AMS results can provide substantial information that can be used in combination with other methods to obtain insights concerning the internal deformation of small volumes of lava.

In particular, it has been shown experimentally that AMS can be a good indicator of the time elapsed between the end of internal shearing and the effective solidification of magmatic material. Cañón-Tapia and Pinkerton (2000) provided evidence indicating that larger degrees of anisotropy are preserved when uniform shearing takes place close to the effective solidification of the rock; whereas, small degrees of anisotropy might be related to either small amounts of shearing or to shearing that ends at a relatively high temperature, leaving enough time for the relaxation of the acquired mineral fabric before solidification. In addition, Cañón-Tapia and Castro (2004) indicated that small variations of the local stretching direction over a few centimeters could be detected by examining the degree of anisotropy and shape of the susceptibility tensor (A and B parameters, respectively) that are obtained by combining the magnitudes of the principal susceptibilities. Consequently, those two parameters are also reported here. The AMS results are then used as a starting point to make a preliminary assessment of the validity of the available mechanisms of formation of volcanic bombs.

\section{Sample selection and measurement}

Because this is the first time that AMS is used to measure the fabric of volcanic bombs, there were many unresolved technical questions that required to be addressed first. The main restriction imposed at the beginning of the study concerned specimen size. Standard specimens used to measure AMS are either cylinders of $2.5 \mathrm{~cm}$ diameter and $2 \mathrm{~cm}$ height, or cubes of $8 \mathrm{~cm}^{3}$; besides, a minimum of five specimens is required to evaluate consistency. The number and size of the specimens required from each bomb therefore precluded, a priori, a study of small-size bombs that were not capable of producing the required number of specimens of standard size. Thus, bomb selection was necessarily biased towards those of relatively large size. In addition, it was 
not clear if the AMS signal was strong enough to yield significant results if measured on volcanic bombs. For that reason, this pilot study reports the results of only four bombs (Fig. 3). The composition of all four bombs is basaltic. The first three bombs came from the top of Mauna Kea volcano, Hawaii. Samples from these bombs were obtained in the field with a gasolinepowered drill, cooled with water. The samples were oriented relative to the direction of elongation of the bombs, which for the purposes of result display was arbitrarily made to coincide with the N-S direction. The fourth bomb came from the San Quintin volcanic field, Baja California, Mexico. Samples from the San Quintin bomb were obtained by slicing one corner of the bomb into cubes in the laboratory. Since this bomb was nearly spherical in shape, there was no particular direction of preference, and therefore all the samples were oriented relative to an arbitrarily selected orientation designed as N-S on the diagrams, and an equally arbitrarily defined up-down axis. The samples thus obtained define a "vertical" profile that extends from the rind to the center of the bomb.

Besides testing whether the AMS signal was strong enough to detect any variation between contrastingly different morphological bomb types, part of this study was designed to test the influence of sample size, and to explore the possibility of using small size samples in future studies. For this reason, two groups of specimens were collected from the San Quintin bomb. The first group was of cubes with a volume of $8 \mathrm{~cm}^{3}$. The second group was formed by cubes with a volume of $1 \mathrm{~cm}^{3}$ on average. Specimens of the second group were obtained from a slice of rock produced during the cutting of the first set. Thus, the second set of samples constitutes a profile adjacent to the first, covering nearly the same extension within the bomb, but with a larger number of specimens than the first set.
The AMS of all specimens was measured using a Kappabridge KLY-4 instrument at the Laboratory of Paleomagnetism and Rock Magnetic Properties at CICESE. The parameters used to represent the degree of anisotropy and the shape of the susceptibility tensor were the A and B parameters defined by Cañón-Tapia (1994). Regions of confidence around the mean orientation of the principal susceptibilities were calculated using the Hext-Jellinek approach (Jelinek 1978).

\section{Results}

The orientation of the principal susceptibilities of all the specimens measured is shown in Fig. 4. The larger bread-crust bomb (BB1) yields principal susceptibility axes almost uniformly distributed in all directions, but the regions of confidence around the mean susceptibility tensor indicate that $k_{\text {int }}$ and $k_{\min }$ axes tend to be more difficult to be distinguished from each other than $k_{\text {int }}$ from $k_{\max }$ axes. Those observations are compatible with the low degree of anisotropy and tendency towards more oblate shapes (as indicated by the negative B values) displayed on the diagram of Fig. 5. The principal susceptibility axes of the other bread-crust bomb (BB2) tend to be better clustered than on BB1, although an occasional switching between $k_{\max }$ and $k_{\text {int }}$ axes is observed. The diagram of the small size specimens collected from the same bomb (BB2ss) indicates that the $k_{\max }-k_{\text {int }}$ axes have a tendency to define a girdle around the $k_{\min }$ axes that are clustered along a horizontal direction. Due to the arbitrariness of the definition of the N-S orientation of the diagrams, it is not possible to elucidate whether this grouping bears a special significance or not.
Fig. 3 Photographs of the four bombs sampled. a BB1, b BB2, c $\mathrm{SB} 1$, and $\mathbf{d} \mathrm{SB} 2$. Ruler in (b) is $30 \mathrm{~cm}$ long, and $15 \mathrm{~cm}$ on the other pictures
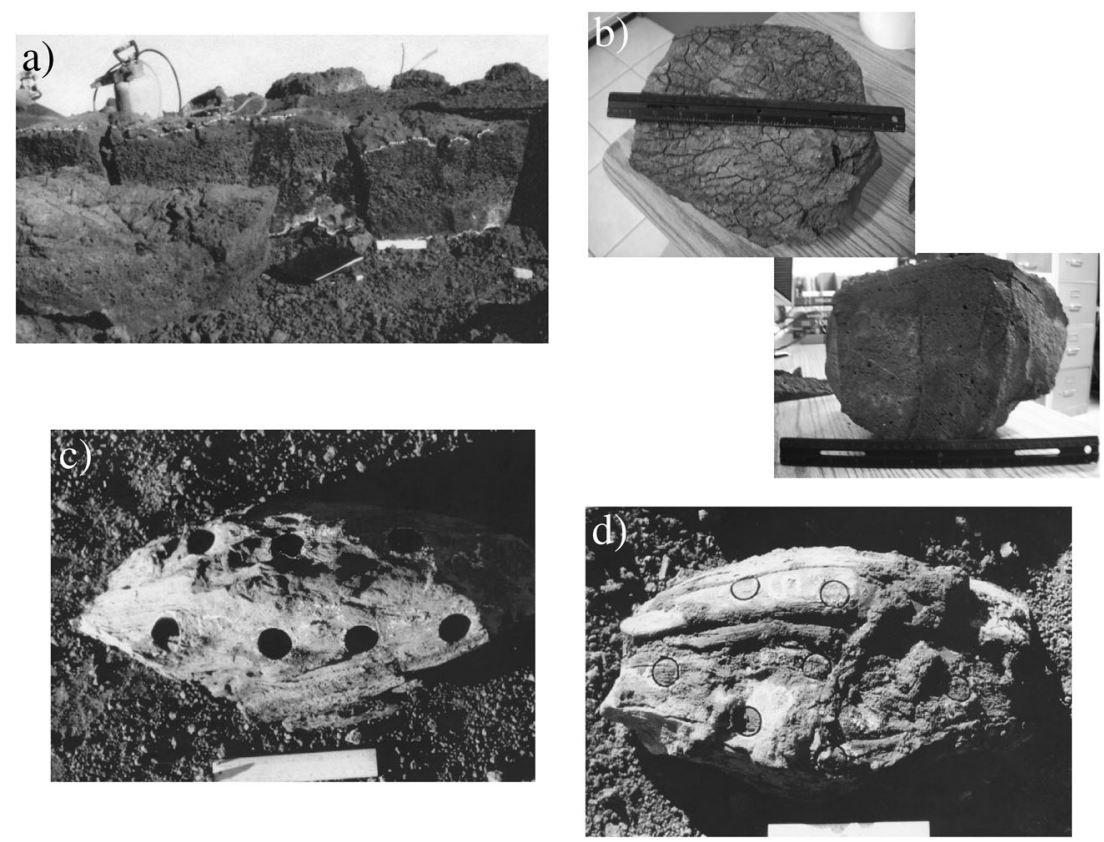
Fig. 4 Equal area projections (lower hemisphere) of the principal susceptibilities of the bombs shown in Fig. 3 e shows the AMS of small size specimens collected from the San Quintin bomb. Red squares- $k_{\max }$, blue triangles- $k_{\text {int }}$, and green circles$k_{\text {min }}$. Larger symbols indicate the orientation of the mean tensor, and the ellipses around those means indicate the corresponding regions of confidence
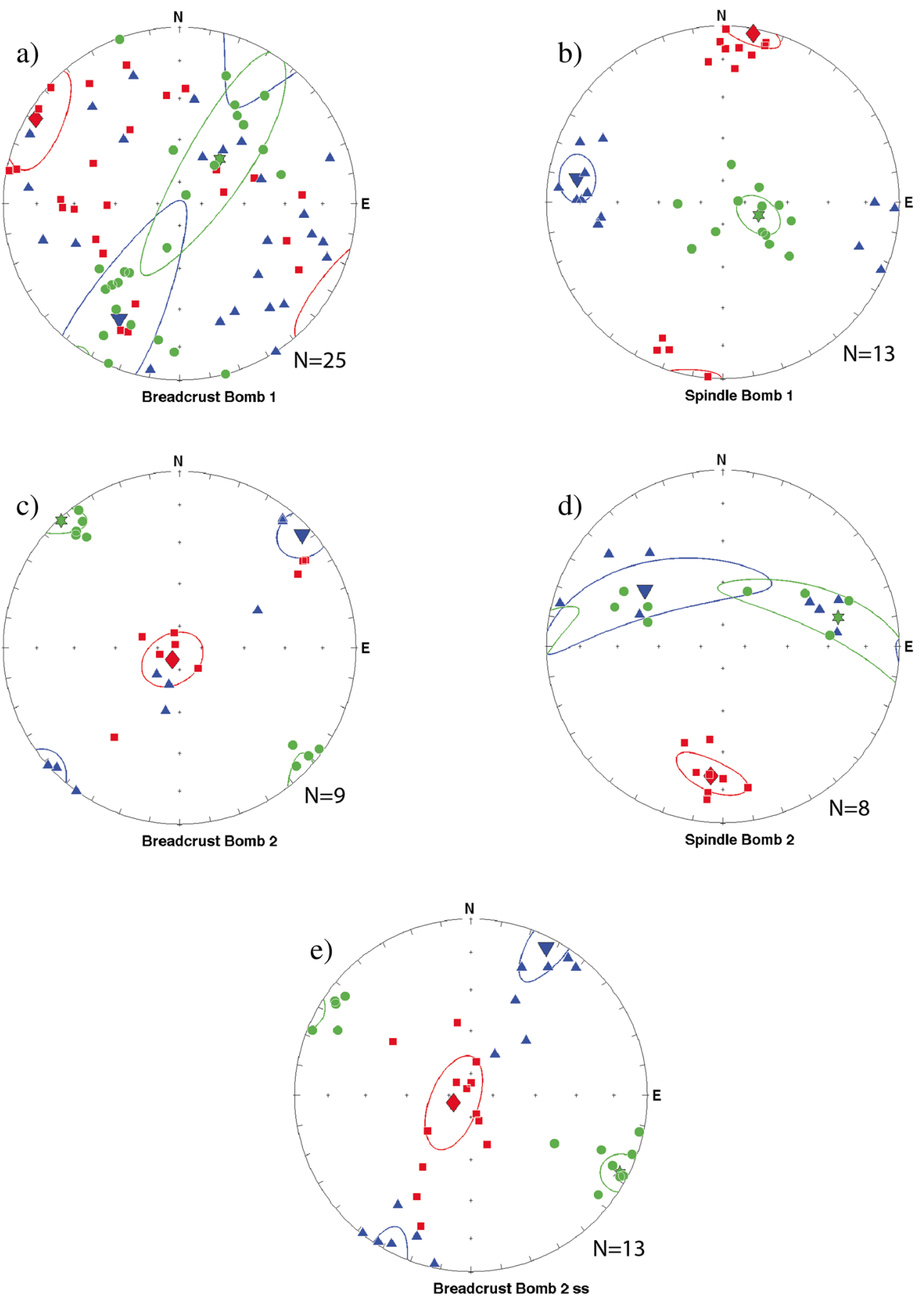

In contrast, the $k_{\max }$ axes of both spindle bombs are subparallel to the direction of elongation of the bomb (N$\mathrm{S}$ on the diagrams). The shape of the regions of confidence around the mean principal susceptibilities of the spindle bomb 2 (SB2) reflects the tendency of those samples to display a prolate susceptibility tensor, similar to the case of BB1. The higher degree of anisotropy of the SB2 samples, however, contributed to producing individual directions that define clusters more easily identifiable than for the BB1 case.
Figure 5 shows a clear difference between the specimens of both types of bombs. Specimens from the bread-crust type display degrees of anisotropy typically less than $1 \%$; whereas, those from the spindle type commonly have a degree of anisotropy larger than $1.5 \%$. The three samples of the breadcrusted type that have the larger A values are small specimens collected from the outermost parts of the bomb (closer or entirely within the rind). The general shape of the susceptibility tensor is also different between specimens collected from both types of bombs, because the spindle type tends to have a 
Fig. 5 Degree of anisotropy ( $A=\left(1-k_{\min } / 2 k_{\max }-k_{\text {int }} /\right.$ $\left.\left.2 k_{\max }\right) \times 100\right)$ versus shape parameter $\left(B=\left(k_{\text {min }} / k_{\text {max }}-2 k_{\text {int }} t\right.\right.$ $\left.k_{\max }+1\right) \times 100$ ). Red symbols are from spindle bombs, and black are from bread-crust bombs. Circles, SB1; inverted triangles, SB2; stars, BB1; triangles, BB2 regular size specimens; and squares, $\mathrm{BB} 2$ small size specimens

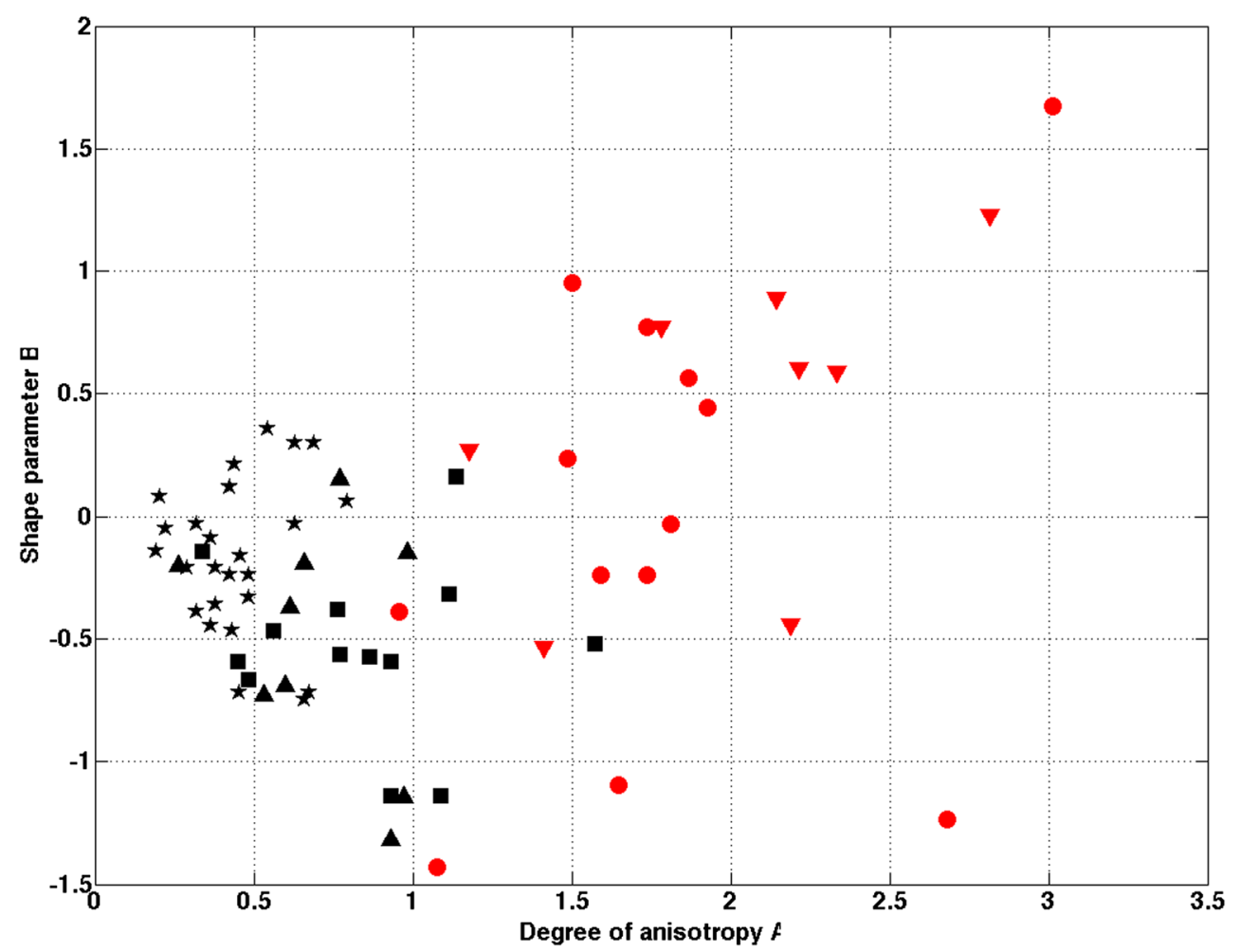

larger number of specimens with a prolate susceptibility tensor (positive values of the B parameter), whereas the shape typical for the bread-crust specimens is oblate (negative values of the B parameter). The tendency for oblate shapes is preserved regardless of the size of the specimens on BB2.

\section{Discussion}

\section{AMS insights}

The difference in the degree of anisotropy observed on Fig. 5 suggests a fundamental difference in the mechanism of formation of the bombs studied here. One condition required to preserve large degrees of anisotropy is the continuous shearing of the lava very close to an effective solidification point (CañónTapia and Pinkerton 2000). Even if deformation during flow is large enough to momentarily produce a relatively large degree of anisotropy, the degree of anisotropy of the solid sample might be rather small if the motion producing the deformation stops when the lava is still fluid. Consequently, the presence of large degrees of anisotropy on the spindle bombs indicates that deformation took place very close to the time of effective solidification of the lava on the bombs. This effective solidification took place not only near the surface, but also includes the internal (central) parts of the bombs. On the other hand, the small degree of anisotropy of the bread-crust bombs indicates that the lava on their internal parts was already stationary when it achieved its effective solidification point, independently of any previous deformation that it might have experienced. The slightly larger values of the degree of anisotropy displayed by the small-size specimens of the San Quintin bread-crust bomb are compatible with this interpretation, because they actually suggest that the external parts of the bombs (closer to the rind), or very close to its center, experienced some amount of deformation very close to their solidification, whereas the intermediate parts of the bomb did not.

The parallelism of the $k_{\max }$ axes on the spindle bombs and the predominance of prolate shapes of the susceptibility tensor are also compatible with the above interpretation. Furthermore, these other two sources of information provide additional clues concerning the type of deformation that the spindle bombs experienced. Although in some special circumstances $k_{\max }$ axes can be perpendicular to the local extension direction, the tendency is to have $k_{\max }$ axes parallel to local extension (Cañón-Tapia and Castro 2004; Cañón-Tapia and Pinkerton 2000). Also, susceptibility tensors displaying a preferred prolate shape tend to be associated with elongation regimes. In contrast, oblate susceptibility tensors and a marked preferred orientation of $k_{\min }$ axes commonly indicate the presence of compaction-regimes. Thus, the orientation of the principal susceptibilities and the preferred shape of the susceptibility tensor of spindle bombs suggest that the shape of the bomb was acquired as the result of elongation that took place very close to the solidification of the entire bomb; whereas, the principal susceptibility axes and susceptibility tensor of the bread-crust bombs is more compatible with either a compaction regime or with cooling in the absence of external stresses. 
Based on the information provided by the AMS results, it is possible to go a step further and re-examine the various mechanisms of formation of volcanic bombs summarized in Fig. 2a, b. The action of air drag and surface tension forces is expected to be stronger on the fluid closest to the surface of the bomb, and to decrease in intensity as the lava inside the bomb is closer to its center. In this case, a systematic variation of magnetic fabric as a function of position relative to the surface of the bomb would be expected. If the interior of the bomb behaved as a Newtonian fluid, drag-related shearing should extend from the surface to its very center. Otherwise, its influence would be limited to a region closer to the surface, where shearing is more intense. The AMS results of the two morphologies studied here suggest that a variation in the amount of shear is only observed very close to the surface ( $\sim 1$ or $2 \mathrm{~cm})$, and is detectable only if small size specimens are used on the measurement. If large, standard size specimens are used, the AMS signal becomes dominated by the fabric of the interior of the bomb and does not display a systematic variation as a function of depth. For this reason, the influence of drag-related forces as agents controlling the shape acquisition of large volcanic bombs seems to be restricted to their surface and cannot be considered to be responsible for any deformation on their internal parts.

Similarly, a rotational movement having the largest dimension of spindle bombs as axis (rotation 2 in Fig. 2a) can be eliminated, because the orientation of the shear responsible for the elongation of the bomb is not parallel with the largest direction of the bomb, and therefore it would not explain the observed orientation of $k_{\max }$ axes. In contrast, a rotational movement around an axis perpendicular to the longest direction of the bombs (rotation 1 in Fig. 2a) is more compatible with the AMS observations.

It must be noted that the measured orientation of the principal susceptibilities of samples SB1 and SB2 is also compatible with the orientation of shear associated to the mechanism shown in Fig. 2b. The only constrain imposed would be that such deformation also took place close to the solidification point of lava, so that the orientation of principal susceptibility axes could be preserved.

Consequently, based on the information provided by AMS measurements, the two favored mechanisms of elongated bomb formation are those of rotation 1 in Fig. $2 \mathrm{a}$ and that illustrated on Fig. 2b.

\section{Analytical assessment of current models of bomb formation}

Since AMS results favor the occurrence of two mechanisms of formation (rotation1 and ejection in Fig. 2), it is reasonable to focus only on those two mechanisms to examine them from an analytical point of view. The analyses made on this section are independent of the AMS measurements and highly simplified.
Nevertheless, the general comments presented here provide guidelines of several aspects that can be investigated in more detail in future studies.

\section{In-flight rotation}

The stresses in any body that rotates about a single axis are proportional to the square of its radius, its density, and the square of the angular velocity (Timoshenko 1934). Due to the influence of density, even small angular velocities might result in stresses of a few thousands of Pascals, making relatively easy to deform lavas of moderate viscosities $(\sim 1500 \mathrm{~Pa}$ $\mathrm{s})$ in a few seconds. Because time of travel has been documented to be on the range 1 to $10 \mathrm{~s}$ (Vanderkluysen et al. 2012; Wright et al. 2007), it is reasonable to accept that some bombs might have formed through this mechanism. It must be noted, however, that the larger times required for cooling of the larger bombs should provide ample opportunity for relaxation of any fabric acquired during fly, unless the lava behaves as a nonNewtonian fluid. The preservation of the AMS fabrics described above is a strong indication of a non-Newtonian behavior that therefore needs to be considered in future studies.

Apart from the rheological behavior of the lava forming the bomb, there is another aspect concerning the time of cooling necessary for the preservation of the deformation that needs to be examined. Vanderkluysen et al. (2012) have shown that most pyroclastic particles experience a well-defined cooling trend during their flight, landing with a temperature $70 \%$ lower than the starting temperature. Fifteen percent of the pyroclasts landed with a temperature $80 \%$ of the starting, and $9 \%$ of the pyroclasts experienced an increase on their surface temperatures. If the glass transition is set to $700{ }^{\circ} \mathrm{C}$, this means that the starting temperatures of bombs should be between $900{ }^{\circ} \mathrm{C}$ and $1000{ }^{\circ} \mathrm{C}$. Otherwise, the deformation acquired during the initial expansion of gas would be destroyed upon impact on landing. This would explain why volcanic bombs tend to be more abundant on top of the deposits being associated with the increasing viscosity during the waning stages of an eruption, rather than being interspersed with scoria or other pyroclasts formed during the main phases (Wentworth and Macdonald 1953). This range in temperatures is likely to be different for the various bomb morphologies, as suggested by the differences on their respective degrees of anisotropy. Such assertion, however, needs to be evaluated by using a more extensive population of volcanic bombs, and is part of an ongoing study.

\section{Deformation upon leaving the magma pool}

I now refer to the mechanism illustrated in Fig. 2b. This mechanism has been less studied than the deformation upon rotation, and therefore deserves a more extended treatment. As mentioned above, this mechanism has been invoked mainly 
to explain the formation of a specific type of achnelith known as Pele's hair.

A key element on the mechanism of formation of Pele's hair pointed out by several authors (Duffield et al. 1977; Heiken 1972, 1974; Wentworth 1938) is that such structure forms from droplets that emanate directly from the magma pool and that are stretched into threads before completely breaking out from that pool. A similar mechanism was described to take place from lava falls associated to changes of slope affecting a moving lava flow. Despite the detailed descriptions that some of those authors offer, however, none of them provides a theoretical foundation that could serve to identify the most relevant parameters controlling the formations of those threads.

Following a similar line of reasoning, Shimozuru (1994) suggested that the conditions for the formation of Pele's hair were similar to those encountered during the formation of ink jets. According to him, the conditions for the formation of Pele's hair and tears depended on the ratio of the Weber and Reynolds numbers, which he called the Pele's number $(=v \times \eta /$ $\sigma$; where $v$ is the velocity of the fluid in the jet, $\eta$ is its viscosity, and $\sigma$ is its surface tension); formation of Pele's hair is favored when Pele's number is large, otherwise Pele's tears form. In the remainder of this section I examine this mechanism in the context of a particle that approaches, deforms, pierces, and moves away from a deformable interface between two fluids, following a trajectory that is perpendicular to the originally undeformed interface(Fig. 6a).

An analytical treatment of this type of movement for the specific case of spherical particles has been made by Geller et al. (2006). Here, I summarize the most important aspects of their work using conditions relevant for the formation of volcanic bombs. In this context, the spherical particle is the core of the bomb, and the wrapping of magma is the bomb body. According to Geller et al. (2006) the movement illustrated in Fig. 6a leads to two modes of interface deformation: a film drainage mode in which the envelope around the sphere thins out very rapidly (and consequently no bomb is produced), and a tailing mode in which the sphere deforms the interface remaining encapsulated by the fluid from which it is moving away, forming a thread-like tail. According to those authors, the difference between both situations can be assessed by using two main parameters. The first is $\lambda$, the ratio of the viscosity of the fluid towards which the particle moves (fluid 2 in Fig. 6a, hereafter assumed to be air) divided by the viscosity of the fluid in which the particle is originally (fluid 1 in Fig. 6a, hereafter considered to be magma). The second parameter of interest is $\mathrm{Ca}$, the ratio of the characteristic viscous stress at the interface relative to surface tension $(\mathrm{Ca}=\mu \times v / \sigma$; where $\mu$ is the viscosity of magma, $v$ the velocity of the particle, and $\sigma$ the surface tension at the interface). A third parameter, $\mathrm{Cg}$, defined as the ratio of characteristic viscous stress relative to buoyancy forces $\left(\mathrm{Cg}=\mu \times v /\left(a^{2} \times g \times \Delta \rho\right)\right)$; where $a$ is the radius of the particle that is envisaged as a sphere, $g$ is the acceleration due to the action of gravity, and $\Delta \rho$ is the density difference between the magma and the air) is also of some interest, but since $\mathrm{Cg}$ is related to the form in which the shape of the interface deforms upon approach of the sphere from below, not exerting a large influence on the total amount of fluid that can be carried across the plane by entrainment, it can be neglected for the present purposes. Thus, although the exact outcome depends on the details of the particular situation, Geller et al. (2006) indicate that as long as $\lambda$ is close to zero and $\mathrm{Ca}$ is of the order of 0.1 or larger, a tail will be formed. In contrast, $\lambda$ equal to 1 and a very small $\mathrm{Ca}$ lead to film drainage behavior.

Due to the large differences that exist between the viscosity of the air and that of the magma from where the sphere is ejected, $\lambda$ is expected to be very small on situations relevant for the formation of volcanic bombs. The viscosity of basalt can be as low as $30 \mathrm{~Pa}$ s (if pure liquid at temperatures larger than $1150{ }^{\circ} \mathrm{C}$ ), but most typically will be on the range 200 $1300 \mathrm{~Pa}$ s for temperatures lower than $1140^{\circ} \mathrm{C}$ (Ishibashi and Sato 2007; Parfitt and Wilson 2008); in contrast the viscosity of air is equal to $1.71 \times 10^{-5} \mathrm{~Pa}$ s. Using those values, $\lambda$ is expected to be on the range $1.31 \times 10^{-8}$ to $8.5 \times 10^{-8}$. It remains to estimate the value of $\mathrm{Ca}$. Taking typical values of surface tension between $0.05-0.1 \mathrm{~N} \mathrm{~m}^{-1}$ (Parfitt and Wilson 2008) and exit velocities of particles between 26 and $71 \mathrm{~m} \mathrm{~s}^{-1}$ (Vanderkluysen et al. 2012), Ca is found to take values of the order of $10^{5}$. These values indicate that in most cases of volcanic interest, a particle approaching the surface of a magma pool from below will leave the pool of magma wrapped by a film carrying behind a tail of magma. The next step in the analysis is therefore to assess whether such exit velocities are reachable in volcanic conditions.

The main force responsible for the movement of a particle (gas bubble or solid with a smaller density than the surrounding lava) towards and beyond the deformable interface is in this case buoyancy. As a first approximation, disregarding gas expansion, the velocity of the particle will be controlled by the density difference between the particle and the magma, the size of the particle, and the magma viscosity. Entirely assuming a Stokes (laminar) flow, it is possible to calculate the terminal velocity of a spherical particle moving within the magma, as $v=2 / 9 \times\left(a^{2} \times g \times \Delta \rho / \mu\right)$ (Batchelor 1991). Figure $6 \mathrm{~b}$ shows that the velocity of particles below $0.8 \mathrm{~m}$ will not reach $20 \mathrm{~m} \mathrm{~s}^{-1}$, which is a lower bound for the ejection velocity of particles, unless the density difference is extremely large $\left(2500 \mathrm{kgm}^{-3}\right)$. The same figure shows that for very viscous magma (1300 Pa s) not even such a large density difference suffices to reach the minimum ejection velocity required to produce tails of magma that later become tear or spindleshaped bombs. For this reason, even when it seems 
Fig. 6 a Two possible behavior of a fluid-fluid interface that is approached by a moving particle. b Particle radius versus ascent velocity as a function density difference and magma viscosity. Density differences are as indicated on the top left corner. Two curves with the same symbol have the same density difference but each represents a different viscosity of magma. Black lines correspond to a viscosity of $1300 \mathrm{~Pa}$ s; whereas, the red lines are for $200 \mathrm{~Pa} \mathrm{~s}$

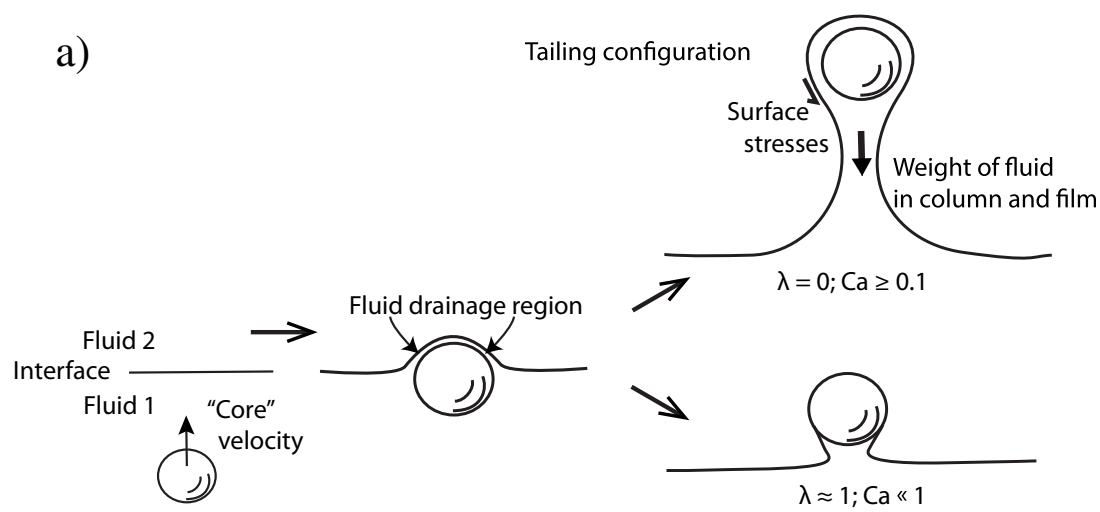

Film drainage behavior

b)

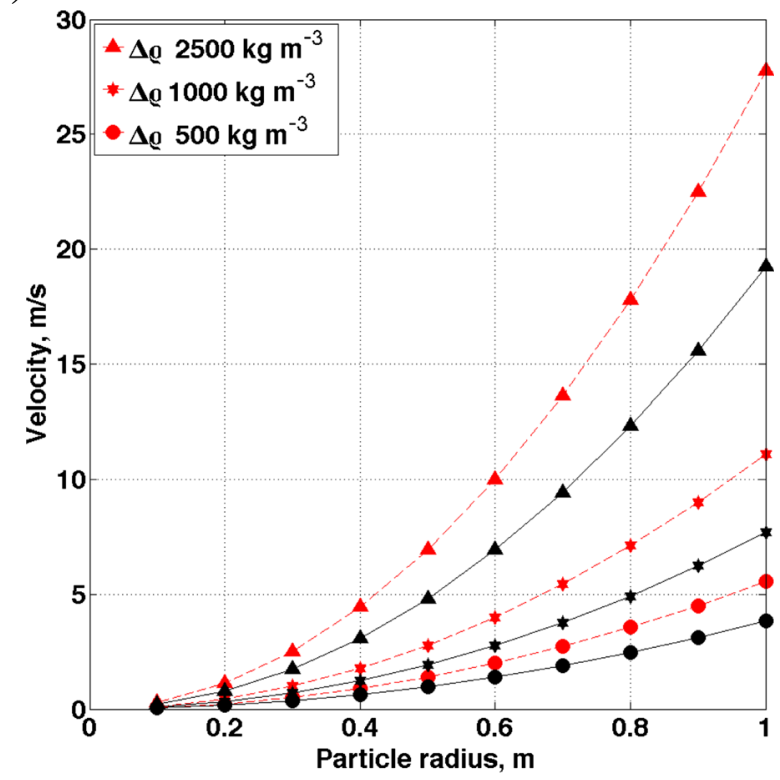

To assess quantitatively the relevance of the forces involved, it is convenient to rely on the analysis made by Wilson (1980) of Strombolian eruptions. According to him, the sudden expansion of the upper part of a gas bubble that has reached the surface of a magma pond is related to the ratio of the internal and atmospheric pressures $\left(P_{\mathrm{i}} / P_{\mathrm{s}}\right)$, and to the ratio of the specific heat of the gases involved $(\gamma)$.

$d=r_{\mathrm{i}}\left(\frac{P \mathrm{i}}{P \mathrm{~s}}\right)^{\frac{1}{3 \gamma}} \ldots$

Towards a general model of formation of volcanic bombs and achneliths On the analysis completed above, the forces associated to the sudden expansion of gas as it reaches the surface, and its subsequent bursting, have been neglected. Nevertheless, those forces provide an additional impetus that under certain circumstances might lead to the formation of volcanic bombs, as will be outlined next. In addition, the bursting of bubbles has been shown to have a direct relationship with the shapes of the particles at a microscopic level (Heiken 1972). Thus, it is of interest to explore the possibility to invoke such a mechanism in a macroscopic context. 
In a sphere, surface deformation is related to linear deformation by the following expression:

Linear deformation $=(\text { Surface deformation }+1)^{1 / 2}-1 \ldots$

In this case, the linear deformation can be envisaged as the stretching or shortening of a segment of a circle passing through the center of the sphere, and having the same initial and final radius. The advantage of considering a linear deformation by combining Eqs. 2 and 3 is that this type of deformation is easier to obtain from solidified bombs than the fractional change in area, for which the three dimensional form of the bomb becomes extremely important. Consequently, for the present purposes a rough indication of deformation was obtained by comparing the final shape of elongated bombs with an assumed bomb of circular cross section at the time of ejection from the magma pond, further assuming that all elongation took place along a single axis. In this form, it is possible to calculate an extreme deformation value corresponding to the linear elongation of the longest axis of the bomb (elongation $=$ [final length - initial length]/initial length). The initial length of the axis can be assumed to be either the smallest or the intermediate axis of the bomb, or (as preferred here) an average of those two. Elongation of spindle bombs estimated from measurements made on 25 bombs range between 0.4 and 2.0, with an average slightly above 1 . These values are used as reference when examining the results shown in Fig. 7b. The curves of that figure show the linear deformation obtained by combining Eqs. 2 and 3 and taking $P_{\mathrm{s}}=100 \mathrm{kPa}$, and $\gamma=1.28$ (Wilson 1980). As it can be seen in the figure, the amount of linear deformation experienced by a thin veneer of magma is large enough to explain the deformation measured in a typical spindle bomb, and consequently, the proposed mechanism is a viable alternative that shall be explored in more detail in future studies, preferably with more data than those presented here. In any case, the orientation of the principal susceptibilities and the associated degree of anisotropy measured in the two spindle bombs of this work, are consistent with this working hypothesis.

\section{Conclusions}

This work shows that AMS can be fruitfully used to constrain models for the mechanism(s) of volcanic-bomb formation. In particular, the degree of anisotropy and shape parameters of two morphologically contrasting bomb types was found to be also different. This work also shows that the use of small specimens can detect subtle differences in AMS within a single bomb. Despite the limited number of samples analyzed here, the AMS signal provides enough evidence to favor two previously outlined mechanisms of formation of volcanic bombs. Although both of those models remain conceptually valid, a preliminary assessment indicates that those models are
Fig. 7 a Scheme showing the effect of the expansion of a bubble of gas that reaches the surface of lava. b Amount of linear deformation experienced by a layer of lava around a bursting bubble as a function of the initial pressure of the bubble

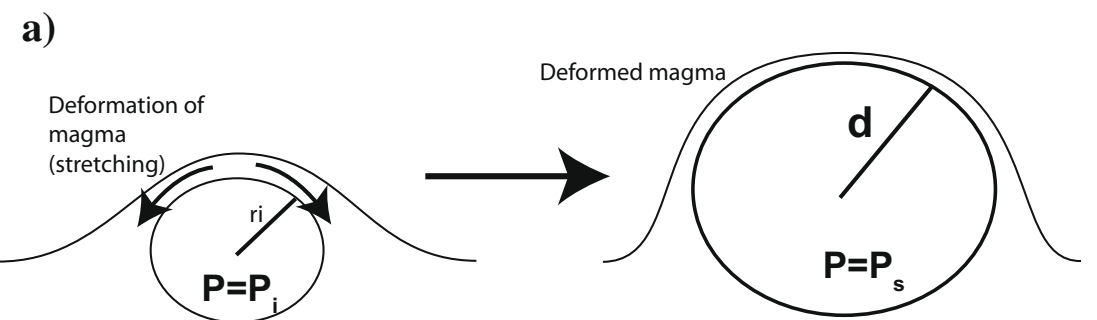

b)

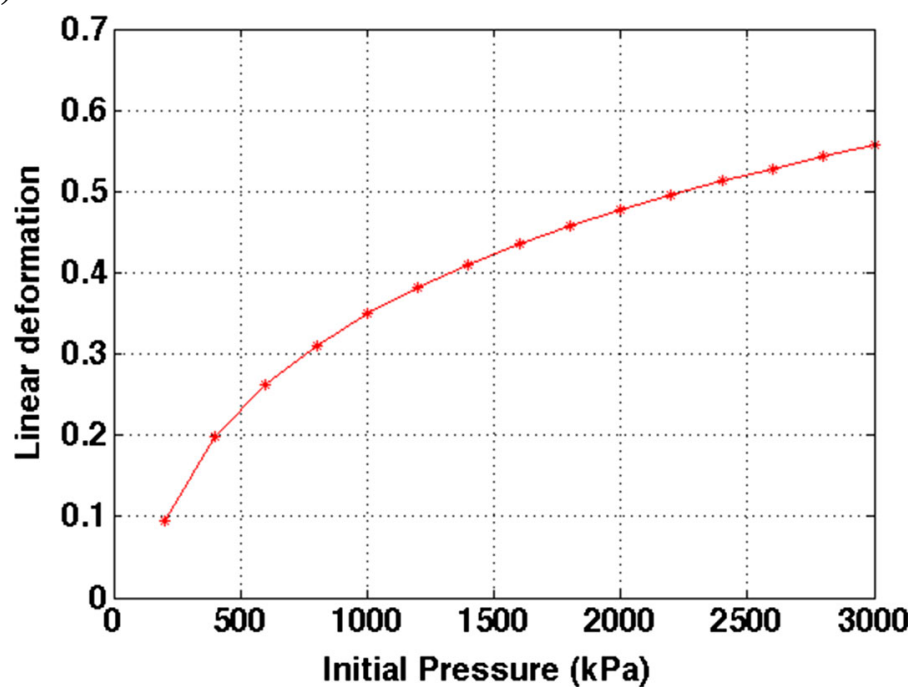


valid only under certain conditions. A third possible mechanism for the acquisition of the shape of bombs was also outlined. This new model involves a two-step process: (1) ejection of a small volume of magma dragged on top of large bubbles of gas that reach the surface of a magma pool and (2) disruption of the ejected magma either as the result of the bursting of the gas bubble, or as a consequence of currents of air that further destabilize already formed jets of magma. To some extent, this mechanism of formation of bombs is analogous to the formation of small pyroclasts as the result of the bursting of bubbles, and therefore indicates a continuum in the formative conditions for smooth vs. angular clasts. The working hypothesis advanced here, based on a limited number of AMS results, is being currently tested in a follow-up study richer in data, and that includes a larger variety of bomb morphologies.

Acknowledgements Comments by L. Vanderkluysen, Lionel Wilson, and an anonymous reviewer on earlier versions helped to keep the reported work on focus and are greatly appreciated. The editorial assistance of $\mathrm{V}$. Acocella is also acknowledged. Support was provided by CONACYT grant CB2012-183116-T.

Open Access This article is distributed under the terms of the Creative Commons Attribution 4.0 International License (http:// creativecommons.org/licenses/by/4.0/), which permits unrestricted use, distribution, and reproduction in any medium, provided you give appropriate credit to the original author(s) and the source, provide a link to the Creative Commons license, and indicate if changes were made.

\section{References}

Batchelor GK (1991) An introduction to fluid dynamics. Cambridge University Press, Cambridge 615 pp

Benage MC, Dufek J, Degruyter W, Geist D, Harpp K, Rader E (2014) Tying textures of breadcrust bombs to their transport regime and cooling history. J Volcanol Geotherm Res 274:92-107

Cañón-Tapia E (1994) AMS parameters: guidelines for their rational selection. Pur Appl Geophys 142:365-382

Cañón-Tapia E, Castro J (2004) AMS measurements on obsidian from the Inyo Domes, CA: a comparison of magnetic and mineral preferred orientation fabrics. J Volcanol Geotherm Res 134(3):169-182

Cañón-Tapia E, Pinkerton H (2000) The anisotropy of magnetic susceptibility of lava flows: an experimental approach. J Volcanol Geotherm Res 98:219-233

Carracedo Sánchez M, Sarrionandia F, Arostegui J, Larrondo E, Ibarguchi JIG (2009) Development of spheroidal composite bombs by welding of juvenile spinning and isotropic droplets inside a mafic eruption column. J Volcanol Geotherm Res 186(3-4):265-279

Carracedo Sánchez M, Arostegui J, Sarrionandia F, Larrondo E, Gil Ibarguchi JI (2010) Cryptoachneliths: hidden glassy ash in composite spheroidal lapilli. J Volcanol Geotherm Res 196(1-2):77-90

Carracedo Sánchez M, Sarrionandia F, Arostegui J, Gil Ibarguchi JI (2015) Silicate glass micro and nanospherules generated in explosive eruptions of ultrabasic magmas: implications for the origin of pelletal lapilli. J Volcanol Geotherm Res 293:13-24

Cas RAF, Wright JV (1987) Volcanic successions modern and ancient. Unwin Hyman, London 528 pp
Dellino P, Liotino G (2002) The fractal and multifractal dimension of volcanic ash particles contour: a test study on the utility and volcanological relevance. J Volcanol Geotherm Res 113:1-18

Duffield WA, Gibson EK Jr, Heiken G (1977) Some characteristics of Pele's hair. Journal of research U.S Geol Surv, 5: 93-101.

Ersoy O, Chinga G, Aydar E, Gourgaud A, Evren Cubukcu H, Ulusoy I (2006) Texture discrimination of volcanic ashes from different fragmentation mechanisms: a case study, Mount Nemrut stratovolcano, eastern Turkey. Comput Geosci 32(7):936-946

Ersoy O, Aydar E, Gourgaud A, Bayhan H (2008) Quantitative analysis on volcanic ash surfaces: application of extended depth-of-field (focus) algorithm for light and scanning electron microscopy and 3D reconstruction. Micron 39(2):128-136

Fisher RV, Schminke HU (1984) Pyroclastic rocks. Springer-Verlag, Berlin $472 \mathrm{pp}$

Francis P (1995) Volcanoes. A planetary perspective. Oxford University Press, Oxford $443 \mathrm{pp}$

Geller AS, Lee SH, Leal LG (2006) The creeping motion of a spherical particle normal to a deformable interface. J Fluid Mech 169(-1): 27

Heiken G (1972) Morphology and petrography of volcanic ashes. Geol Soc Am Bull 83:1961-1988

Heiken G (1974) An atlas of volcanic ash. Contrib Earth Sci 12:1-101

Heiken G, Wohletz K (1985) Volcanic ash. University of California Press, Berkeley

Hoblitt RP, Harmon RS (1993) Bimodal density distribution of cryptodome dacite from the 1980 eruption of Mount St. Helens, Washington. Bull Volcanol 55:421-437

Hrouda F (1993) Theoretical models of magnetic anisotropy to strain relationship revisited. Phys Earth Planet Inter 77:237-249

Hrouda F, Chlupacova M, Schulmann K, Smid J, Zavada P (2005) On the effect of lava viscosity on the magnetic fabric intensity in alkaline volcanic rocks. Stud Geophys Geod 49:191-212

Ishibashi H, Sato H (2007) Viscosity measurements of subliquidus magmas: alkali olivine basalt from the Higashi-Matsuura district, Southwest Japan. J Volcanol Geotherm Res 160(3-4):223-238

Jelinek V (1978) Statistical processing of anisotropy of magnetic susceptibility measured on groups of specimens. Stud Geophys Geod 22: $50-62$

Junqueira-Brod TC, Brod JA, Thompson RN, Gibson SA (1999) Spinning droplets - a conspicuous lapilli-size structure in Kamafugitic diatremes of Southern Goiás, Brazil. Rev Bras Geosci 29:437-440

Leibrandt S, Le Pennec J-L (2015) Towards fast and routine analyses of volcanic ash morphometry for eruption surveillance applications. J Volcanol Geotherm Res 297:11-27

Liu EJ, Cashman KV, Rust AC (2015) Optimising shape analysis to quantify volcanic ash morphology. GeoResJ 8:14-30

Lockwood JP, Hazlett RW (2010) Volcanoes: global perspectives, WileyBlackwell, Chichester $541 \mathrm{pp}$

Loock S, Diot H, Van Wyk de Vries B, Launeau P, Merle O, Vadeboin F, Petronis MS (2008) Lava flow internal structure found from AMS and textural data: an example in methodology from the Chaine des Puys, France. J Volcanol Geotherm Res 177:1092-1104

Macdonald GA, Abbott AT, Peterson FL (1986) Volcanoes in the sea: the geology of Hawaii. University of Hawaii Press, Honolulu 517pp

Ollier C (1988) Volcanoes. Basil Blackwell Ltd., Oxford 228 pp

Parfitt EA, Wilson L (2008) Fundamentals of physical volcanology. Blackwell Publishing, Carlton $230 \mathrm{pp}$

Petronis MS, Delcamp A, van Wyk de Vries B (2013) Magma emplacement into the Lemptégy scoria cone (Chaine des Puys, France) explored with structural, anisotropy of magnetic susceptibility, and paleomagnetic data. Bull Volcanol 75:753-775

Rausch J, Grobéty B, Vonlanthen P (2015) Eifel maars: quantitative shape characterization of juvenile ash particles (Eifel volcanic field, Germany). J Volcanol Geotherm Res 291:86-100 
Reck H (1915) Physiographische studie über vilkanische bomben. Immanuel Friedlaender, Napoli

Riley CM, Rose WI, Bluth GJS (2003) Quantitative shape measurements of distal volcanic ash. J Geophys Res 108. doi:10.1029/2001JB000818

Schmid R (1981) Descriptive nomenclature and classification of pyroclastic deposits and fragments. Geol Rundsch 70:794-799

Sheridan MF, Kortemeier CP (1987) Quantitative analysis of surface features on pyroclasts: an example from the Monte Guardia sequence, Lipari. In: Marshall JR (ed) Clastic particles. Van Nostrand Reinhold, New York, pp 122-134

Sheridan MF, Marshall JR (1983) Interpretation of pyroclast surface features using SEM images. J Volcanol Geotherm Res 16:153-159

Shimozuru D (1994) Physical parameters governing the formation of Pele's hair and tears. Bull Volcanol 56:217-219

Simakin AG, Armienti P, Epel'baum MB (1999) Coupled degassing and crystallization: experimental study at continuous pressure drop, with application to volcanic bombs. Bull Volcanol 61:275-287

Timoshenko S (1934) Theory of elasticity. McGraw-Hill Book Company, Inc., New York 416 pp

Tsuya H (1939) On the form and structure of volcanic bombs, with special reference to the origin of the basaltic bombs from volcano Huzi (Fuji). Bull Earthq Res Inst Univ Tokyo 17:809-825

Tsuya H (1941) On the form and structure of volcanic bombs from volcano Miyake-sima. Bull Earthq Res Inst Univ Tokyo 19:597-611
Vanderkluysen L, Harris AJL, Kelfoun K, Bonadonna C, Ripepe M (2012) Bombs behaving badly: unexpected trajectories and cooling of volcanic projectiles. Bull Volcanol 74(8):1849-1858

Vonlanthen P, Rausch J, Ketcham RA, Putlitz B, Baumgartner LP, Grobéty B (2015) High-resolution 3D analyses of the shape and internal constituents of small volcanic ash particles: the contribution of SEM micro-computed tomography (SEM micro-CT). J Volcanol Geotherm Res 293:1-12

Walker GPL (1969) The breaking of magma. Geol Mag 106:166-173

Walker GPL, Croasdale R (1972) Characteristics of some basaltic pyroclasts. Bull Volcanol 35:303-317

Wentworth CK (1938) Ash formations of the Island of Hawaii, Hawaiian Volcano Observatory

Wentworth CK, Macdonald GA (1953) Structures and forms of basaltic rocks in Hawaii. United States Geological Survey, 98 pp

Williams H, McBirney AR (1979) Volcanology. Freeman, Cooper \& Co., San Francisco 397 pp

Wilson L (1980) Relationships between pressure, volatile content and ejecta velocity in three types of volcanic explosions. J Volcanol Geotherm Res 8:297-313

Wright HMN, Cashman KV, Rosi M, Cioni R (2007) Breadcrust bombs as indicators of Vulcanian eruption dynamics at Guagua Pichincha volcano. Ecuador Bull Volcanol 69(3):281-300 